\title{
MONUMENTO Y RUINA RESTAURADA
}

ACE VEINTE AÑOS, CON MOTIVO de la inauguración del entonces Centro de Arte Reina Sofía, el arquitecto taurado perviva ha de huir de una cosmética de formas materiales aleatorias y, por el contrario, integrar la racionalización de las entidades políticas, culturales, sociales y económicas que constituyen los motivos de su evolución. Desde entonces no se ha cansado de ponerlo en práctica en el ejercicio de su profesión y de repetirlo en las aulas; a través de sus escritos sobre pensamiento y crítica arquitectónica; en la Real Academia de Bellas Artes de San Fernando, a la que pertenece desde 1989, y más recientemente, en la Real Academia Española. Frente al conocimiento razonable, en demasiadas ocasiones se han impuesto la obsesión estética patológica, la homogeneización constructiva o el estrellato de los profesionales a la hora de abordar el proyecto arquitectónico sobre la ciudad de nuestra época.

Patrimonio Histórico. Desde el inicio de su trayectoria profesional usted ha considerado el ejercicio de la arquitectura contemporánea en un marco físico y sociocultural amplio. ¿Ha perdido vigencia este discurso o, por el contrario, detecta que se hayan reafirmado los postulados iniciales de respeto a la biografía del edificio, su valor cultural y los límites del espacio circundante?

Antonio Fernández Alba. La confrontación del nuevo orden económico con las estructuras urbanas del viejo orden político plantea un nuevo escenario que va más allá de los relatos 
espaciales de la arquitectura, evoluciones territoriales y formalizaciones urbanas. Este choque aborda de lleno el protagonismo que adquiere el mundo de los grandes monopolios económicos y su relación con los dictados formales o espaciales que plantea la nueva condición metropolitana, y que se traduce a veces en esas «construcciones de la desmesura» donde me parece que rompen sin pudor lo racional de la forma y la arquitectura ha perdido su sentido.

La urbanización capitalista convencional venía acotada por el desarrollo del modo productivo económico y ofrecía en un primer estadio unas cualidades territoriales como la estabilidad, la homogeneidad, los asentamientos seriados y la consiguiente organización jerárquica de estos asentamientos dentro de las metodológicas del zoning, cultura, vivienda, industria... en definitiva, la ortodoxia de la normativa de los C. I. A. M. (Congresos Internacionales de Arquitectura Moderna), y que de manera tan significativa estuvieron ligados los postulados y realizaciones de la arquitectura contemporánea hasta los finales del siglo precedente.

La urbanización y planificación capitalista avanzada, integrada en unos sistemas de acumulación flexible, presenta unas características morfológicas, por cuanto se refiere al proyecto de la arquitectura, que favorecen sin duda la heterogeneidad y la dinámica de flujos del capital, que tienden a la dispersión y al fragmento, como bien queda narrado en el acontecer urbano y arquitectónico de los finales del siglo XX. Este planeamiento, espacialidad urbana, y proyecto de la arquitectura como señalan algunos analistas, se habría caracterizado como un proyecto o arte de capturas, un método aleatorio de estetizar la ciudad, mediante modelos de una belleza ambigua, belleza basada en unas formas que podríamos calificar de «anarquía progresista». Si debo responder de manera sincera, ante el acontecer de tanto discurso formal por el que atraviesa el proyecto de la arquitectura, me encuentro como en un archipiélago en bruma, entre la resignación asumida o el entusiasmo indeciso ante tan inestable impostura.

$P$. H. Al referirse a la ciudad en la fase de capitalismo global en la que nos encontramos, describe un «modelo automórfico» de espacio metropolitano. ¿Qué rasgos identifican este paradigma y qué consecuencias sobre la cultura urbana tiene su implantación? 
A. F. A. Sin duda, nos encontramos hoy ante un proceso que busca nuevos horizontes en el proyecto de la arquitectura, motivado por estas nuevas relaciones de confrontación y también por el desencanto producido por la revolución industrial, las nubladas ilusiones en torno al optimismo enardecido de la Ilustración, y las conquistas del positivismo científico. Indagación y búsqueda superadora, al menos eso se insinúa, de la crisis de conciencia burguesa tan apasionada por la cultura objetivista y tan próxima al pragmatismo mercantil. Deberíamos entender esta nueva actitud crítica como significativa acción superadora del utilitarismo como ideología, tanto en los territorios de la planificación como en sus apartados espaciales más concretos, propuestas ex novo o reconversiones del patrimonio arquitectónico, ese amplio campo de diseño especifico que no puede dejar de abordar el proyecto de la arquitectura. Creo que estos proyectos y macroedificios deberían reclamar otros valores morfológicos y espaciales que las «audaces» $y$ en ocasiones provocativas especulaciones formales que invadieron los finales del siglo precedente y principios del XXI. Sobre todo superar, me atrevería a señalar, la gran estafa divulgada por el esteticismo moderno, canonizado como trascendencia arquitectónica, a unos edificios que se desmoronan entre el pesimismo de la razón constructiva y el optimismo de su fruición estética y del que tanto se ha nutrido la narración arquitectónica, que ha representado el historicismo de la arquitectura posmoderna y, lo que estimo mas injustificable, sepultando a los maestros constructores del Movimiento Moderno en Arquitectura (MMA), junto a su carga moral, ética y espacial.

Abundaría aún más, los usos y contenidos del espacio hoy se formalizan plásticamente alejados de la reflexión arquitectónica en estos «modelos automórficos», orientados hacia desplazamientos de marcado acento icónico, donde el sujeto urbano desaparece en los celebrados espacios de una arquitectura que, a veces, se consolida en diagonales en el aire y cuya finalidad última son las transacciones del consumo. Basta con observar la composición de sus fachadas, «pieles frías», textura manifiesta de su propia inclemencia, de lo que ayer fue razón de espacio y hoy recinto de desasosiego.

P. H. Los espacios patrimoniales de muchas ciudades han sido ocupados por arquitecturas delirantes, de geometrías oblicuas y formas exóticas, parafraseando sus propias palabras. Todos 
conocemos algunos ejemplos. ¿Nos identificamos los ciudadanos, reconocemos nuestra ciudad en esas propuestas?

A. F. A. En la ciudad podemos encontrar la respuesta, al contemplar en ese laberinto mediático y enloquecedor de lo urbano que amenaza con persuasión la proliferación incontrolable y poliédrica de la imagen. En sus recintos creo que se puede percibir cómo el proyecto de la arquitectura e ingeniería urbana es suplantado por estos «objetos de diseño» y cómo la monumentalización del tráfico rinde pleitesía a la «poética del ruido», sin el recato, en muchas ocasiones, del artificio de sabiduría en el que trabajaba el ingeniero en siglos precedentes.

El proyecto de la arquitectura e ingeniería que opera en la posciudad debe tender por su propia naturaleza a la contemporaneidad, aunque hay que reconocer cómo en parte es anulado por el efecto de diseño que se inmola en las demandas de imagen suscitada por la actualidad del mercado. Contenedores comerciales, macroedificios administrativos, museos... objetos y edificios que muestran la fragilidad de su temporalidad, el carácter efímero de su presencia y la vocación de transferencia rápida y voluble de su espacialidad y, sobre todo, su decidida vocación de ser producto reciclable que se consume en acotados presentes. Espacios y formas urbanas que se construyen y nos fascinan por el efecto de cambio, carentes de todo proyecto ético y emoción poética, son el efecto de la máscara que subyace en las fiestas del carnaval del consumo, donde reconocemos en parte nuestra identidad perdida.

$P$. H. ¿Pueden los arquitectos hoy generar proyectos integradores y ordenadores de los diferentes problemas y programas funcionales y simbólicos en las ciudades? ¿Qué o quiénes lo impiden?

A. F. A. El proyecto del arquitecto se alimenta del pasado con aspiraciones de futuro y debería abrirse paso al proyecto de una arquitectura que no reclamara «fama, ni prestigio», superando la imagen de esos proyectos que aspiran a ser solo objetos contemplados por su bulimia formal, por propuestas y proyectos confiados solo a poder ser habitados.

El realismo que reclama el proyecto «funcional-simbólico» para la ciudad hoy, como en la mayor parte de los productos industriales, es el de la relación calidad-precio, donde priman las utopías totalitarias del consumo. 
La alegoría, en las últimas manifestaciones arquitectónicas, podemos comprobar cómo ha colonizado con la forma al símbolo. Hemos asistido testigos durante todo el siglo XX al debate tensionado para arquitectos e ingenieros entre la razón y la forma; hemos podido acotar sus límites y aforismos, sobre todo ahora ya en el otoño de la función. También pudimos vislumbrar que la razón es mortal, como una fuerza natural controlable aunque de manera parcial y, sobre todo, que es de una sensible fragilidad, y de qué manera la glorificación de lo racional como la emblemática de los símbolos es la falacia con la que opera, y con gran eficacia, no solo el liberalismo económico. Nuestra época, como señalan algunos sectores críticos, «se entrega a la sobreproducción cultural y celebra una cultura hundida en el exceso» (S. Sontang).

El edificio hoy se proyecta y construye como objeto de efecto retórico, adquiere un valor repleto de emociones, a través de los nuevos materiales. Estos materiales se manipulan con las técnicas más sofisticadas arropadas por el derroche de presupuestos desmesurados que subliman la hiperrealidad de la mercancía. El mercado y la Nueva Academia se encargan de inducir la narración de la tendencia, seleccionada por los efectos espaciales que programan y difunden las «marcas» que han de prestar el poder seductor de considerar a la ciudad o al edificio como un texto.

De tal manera aceptamos el poder gratificador de la narración que llegamos a entender que el arquitecto opte en la determinación del proyecto por una especie de invitación sobre la realidad, opción que le permita diseñar una forma radicalmente liberada de la materia, sin que se le pueda achacar de ingenuo formalismo. El edificio se construye como si se tratara de un proceso abierto sin ataduras de usos, funciones y materiales, requiriendo solo lo impredecible en su propuesta final. En definitiva, el proyecto de los arquitectos en las «empresas de diseño de imágenes», en las que milita buena parte del colectivo profesional de la arquitectura e ingeniería, colabora en la redacción de proyectos de las arquitecturas de franquicia, en las redes internacionales del mercado de imagen o en ocasiones en empresas de diseño que consagran determinadas «metáforas visuales», como arquetipos a coleccionar y reproducir.

Entre sus diversificadas variantes se pueden encontrar proyectos y propuestas en una aproximación a lo que podríamos 
denominar un neoconstructivismo, una arquitectura que entiende su concepción espacial como una recuperación de la forma pura del cautivador proceso revolucionario, ahora tecnoindustrial, sin tener en cuenta lo fragmentario y ecléctico del espacio metropolitano donde opera.

Otra variante de esta incontaminada levitación podría contemplarse en trabajos de una cierta actitud neosuprematista, que se orientan hacia la creación de un mundo más humano, a la búsqueda de la forma orgánica, donde formalizar la metáfora tecnoindustrial. Proyectos de raíz contemplativa, actitud esta que junto a las tendencias minimalistas tratan de sustraer la lógica de la construcción del lenguaje arquitectónico y su razón de ser, transformando la realidad construida en un excéntrico formalismo.

$P$. H. ¿Democratizan los medios de comunicación de masas el proyecto arquitectónico al acercarlo al ciudadano o, por el contrario, adoctrinan y venden determinadas «marcas»?

A. F. A. La arquitectura la podemos entender y comprender, entre otras múltiples aproximaciones, como unos espacios y tiempos revelados por la materia. En nuestro tiempo la vivimos en las ciudades unificadas por los medios de información, en recintos y lugares fragmentados por una espacialidad heteróclita, en ocasiones inconciliables, casi siempre dislocadas y con un alto confort tecnológico hasta ahora desconocido. En la posciudad de matriz metropolitana, los espacios de la historia, el patrimonio de la memoria material y cultural, los podemos contemplar bañados en percepciones arcaicas que se mezclan en los recintos de nuestros días con tiempos que construyeron en su época como paisajes de signos y caracteres también heteróclitos, de manera que la propia lectura de lo urbano nos remite a una crónica sentimental de momentos donde aparecen singulares conjuntos monumentales del Siglo de las Luces, junto a rascacielos tangentes a modestos pliegues de la razón funcionalista y marismas de miseria aún en los suburbios como residuos del trabajo esclavo.

Los espacios de la ciudad nos muestran, para quien desea interpretarlos, memoria entumecida, a veces contaminada y deforme, casi siempre absorta en los dogmas del estilo.

No creo que los medios de comunicación, tal como se perfilan y controlan en las actuales relaciones de producción, dispongan de libertad de juicio y crítica para enunciar axiomas 
objetivos. A la belleza obscena que con tanto fervor alimentan los proyectos y arquitecturas de una estética de la ambigüedad, le resulta difícil enunciar postulados críticos que hagan evidente que la ideología estética que hoy cobija la forma y el trabajo de la arquitectura se opone a la ética que debería construir su verdad.

Son voces contadas, muy escasas y a veces incongruentes, las que se permiten enunciar una crítica a muchos de los «proyectos basura» (Koolhaas) en la búsqueda de la arquitectura en torno al paradigma ambiental. Los interrogantes que el hábitat metropolitano reclama requieren clarificar con urgencia que la red es un mercado pero no un espacio cívico.

Ante el enunciado de esta pregunta, señalaría que teoría y crítica deberán reconquistar sus límites en una época de nuevos y acelerados paradigmas. Teoría y crítica que limpie con celo la promiscuidad intelectual y abultada retórica de la banalidad en torno a los sueños oníricos del arquitecto, para que no se cumplan los augurios del profesor F. Castro Flórez, quien recientemente señalaba $(A B C D$, I 5-2 I, 07, pág. 8): «Tienen miedo a una sola cosa, y es que se les arrebate ese sueño»; ojalá, concluía, «el star system de la arquitectura se entregara a una siesta prolongada y nos dejara en paz, pero sobre todo que no lancen nada desde sus alturas olímpicas, porque ya estamos suficientemente aplastados». 